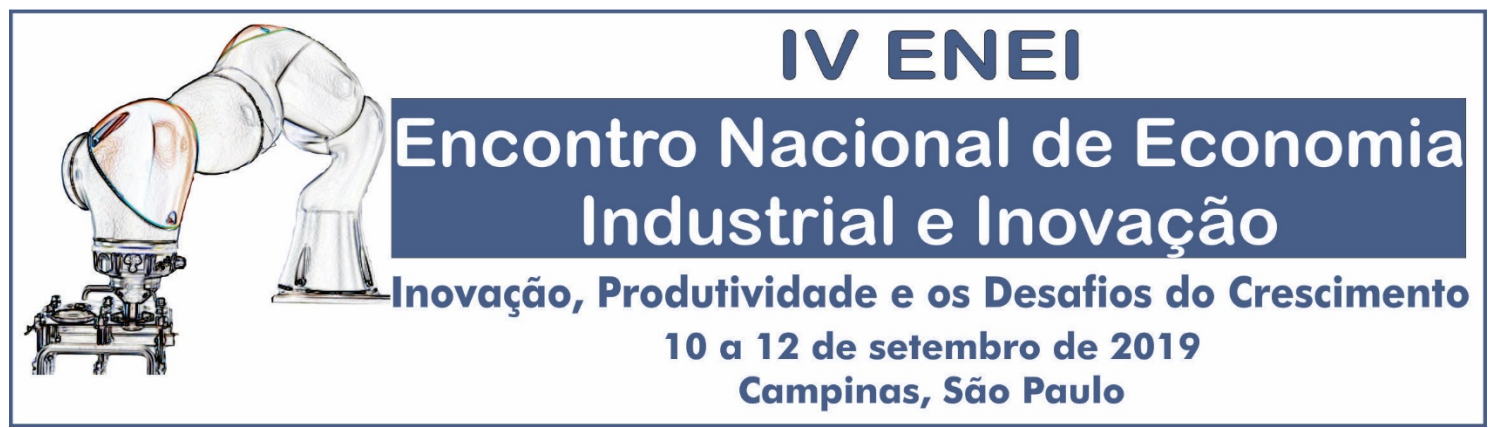

\title{
As capacidades tecnológicas das grandes empresas farmacêuticas nacionais: o caso do Grupo FarmaBrasil
}

Gabriel Faria Guerra e Cunha Universidade Federal do Rio de Janeiro, Instituto de Economia, Brasil gabrielfgcunha@gamil.com

Lia Hasenclever Universidade Federal do Rio de Janeiro, Instituto de Economia, Brasil Universidade Cândido Mendes - Campos, Brasil

\section{Resumo}

O objetivo do artigo é analisar se houve avanço das capacidades tecnológicas das grandes empresas nacionais produtoras de medicamentos, confirmando uma tendência de inflexão positiva observada a partir de 2008 , mesmo após a crise da economia brasileira a partir de 2011. A metodologia adotada é um estudo de caso sobre as capacidades tecnológicas do Grupo FarmaBrasil. O estudo tem como base uma tabulação especial com dados ainda não publicados, coletados pela Pesquisa de Inovação do Instituto Brasileiro de Geografia e Estatística e informações qualitativas obtidas em informações secundárias e entrevistas telefônicas. Os resultados mostraram que o padrão de investimentos em inovação das empresas do Grupo manteve-se com um perfil bastante diferenciado em relação à indústria nacional, assim como, em menor grau, em relação à indústria farmacêutica no país. Fica claro pelos resultados que as empresas estudadas, além de investirem percentualmente sua receita líquida em atividades de pesquisa e desenvolvimento (P\&D) em um patamar bem superior à média da indústria em todas as edições da pesquisa, o que denota capacidade tecnológica endógena, as realizam de maneira continuada e a aquisição de máquinas e equipamentos e $\mathrm{P} \& \mathrm{D}$ externa representam um gasto expressivamente menor em comparação à média da indústria.

\section{Palavras-chave: capacidades tecnológicas; inovação; grandes empresas farmacêuticas nacionais; Grupo FarmaBrasil}

Abstract

The objective of this article is to analyze whether the technological capabilities of the large national drug companies have advanced, confirming a positive inflection trend observed since 2008, even after the Brazilian economic crisis as of 2011. The methodology adopted is a study on the technological capabilities of the FarmaBrazil Group. The study is based on a special tabulation with data not yet published, collected by the Research of Innovation of the Brazilian Institute of Geography and Statistics and qualitative information obtained in secondary information and telephone interviews. The results showed that the pattern of investments in innovation of the Group's companies remained quite different in relation to the domestic industry, and to a lesser degree, in relation to the pharmaceutical industry in the country. It is clear from the results that the companies studied, in addition to investing their net revenue in research and development (R \& D) activities at a level well above the industry average in all editions of the research, which denotes endogenous technological capacity, and 
the acquisition of machinery and equipment and external R \& D represents an expense significantly lower than the industry average.

Keywords: technological capabilities; innovation; large national pharmaceutical companies; Group FarmaBrasil

Área Temática: 5.7 Inovação, competências e competitividade JEL: O3, O31, O32 


\section{Introdução}

A indústria brasileira alcançou elevados níveis de adensamento produtivo em resultado do modelo de substituição de importações. As reformas estruturais dos anos 1990 e a liberalização comercial trouxeram a redução do preço dos bens de capital e insumos importados com maior tecnologia agregada, induzindo a sua escolha frente àqueles produzidos localmente e, assim, deslocando a produção e os esforços tecnológicos associados para outros países. Os principais eventos resultantes foram o agravamento do hiato tecnológico frente aos países desenvolvidos e a retração dos investimentos em pesquisa e desenvolvimento - P\&D (MOTA et al., 2012).

Um mercado mais aberto e, além disso, o reconhecimento para o setor da proteção da propriedade intelectual e o aumento do seu padrão de proteção com a assinatura do Acordo sobre Aspectos dos Direitos de Propriedade Intelectual Relacionados ao Comércio (Acordo TRIPS - Agreement on Trade-Related Aspects of Intellectual Property Rights) pelo Brasil em 1994, somados às melhores capacidades financeiras e tecnológicas das grandes empresas transnacionais, colocaram as empresas farmacêuticas do Brasil em condições de concorrência muito desfavoráveis e limitaram os estímulos e as oportunidades para capacitação tecnológica (TORRES, 2015).

Contudo, em 1999, a aprovação da Lei dos Genéricos (Lei no 9.787/1999) produziu condições para o crescimento e consolidação da indústria farmacêutica nacional. A partir dessa lei, aumenta-se a participação de mercado e maior alcance de uma escala competitiva das empresas farmacêuticas nacionais. A aprovação da Lei dos Genéricos que estabeleceu as exigências dos testes de bioequivalência e biodisponibilidade para o registro de medicamentos genéricos, e a criação da Agência Nacional de Vigilância Sanitária (Anvisa; Lei no 9.782/1999), produziram as condições para o ressurgimento da indústria nacional, que atinge uma participação de $45 \%$ do mercado doméstico em 2010, após grande desafio tecnológico de modernização para alcançar essa participação. Vale lembrar que a política de genéricos não foi uma política estritamente industrial, já que seu objetivo era baratear as compras públicas para reduzir os gastos com medicamentos e facilitar o acesso dos mesmos para a população. Entretanto, funcionou como um estímulo inicial à modernização e capacitação tecnológica das empresas nacionais (CALIARI; RUIZ, 2013).

Essa estratégia, portanto permitiu que as empresas nacionais recuperassem suas parcelas de mercado, mesmo com os preços dos genéricos regulados abaixo dos medicamentos de referência. A oferta doméstica de medicamentos genéricos cresceu rapidamente, mas não induziu a verticalização dos seus insumos. Em consequência, o aumento da sua demanda foi atendido pela importação, gerando um forte déficit comercial setorial. A política de medicamentos genéricos foi bem sucedida em termos de escala de produção e distribuição, ajudando algumas empresas nacionais a figurarem entre as maiores do mercado nacional. No entanto, as capacitações tecnológicas foram limitadas à modernização das empresas e adequação às exigências de qualidade dos produtos genéricos.

Adicionalmente é importante notar que essa janela de oportunidade tem limites em função de dois aspectos. De um lado, o padrão de concorrência na indústria não é via preços, mas via inovações e, de outro, a produção de genéricos, ainda que seja uma inovação para o país, pode limitar a competitividade das empresas ao mercado local e torna-as dependentes do vencimento das patentes para o lançamento de novos produtos (PALMEIRA FILHO, 2013).

Portanto, há ainda grandes desafios por parte das empresas farmacêuticas nacionais de se desenvolverem em um momento histórico de crescente abertura comercial, forte presença das empresas transnacionais e proteção patentária consolidada, na medida em que a 
concorrência se dá em bases desiguais. Além disso, a inovação farmacêutica é uma das mais custosas e complexas da indústria e os casos de catching-up tecnológico nessa indústria são raros.

A pergunta de pesquisa que guiará o artigo será: em que medida as empresas nacionais aumentaram os seus esforços de inovação e melhoraram o seu posicionamento no mercado através da introdução de patentes e inovações, mesmo frente à perda de dinamismo da economia brasileira desde 2011 e crise de 2015, que teve como consequências uma forte recessão econômica, levando a um recuo no produto interno bruto (PIB) por dois anos consecutivos. A economia contraiu-se aproximadamente 3,8\% em 2015 e 3,6\% em 2016, gerando aumento abrupto no desemprego, que atinge no auge mais de 14 milhões de brasileiros ${ }^{1}$.

O objetivo do artigo é analisar se houve avanço das capacidades tecnológicas das grandes empresas nacionais produtoras de medicamentos, confirmando uma tendência de inflexão positiva nos esforços inovativos dessas empresas, observada a partir de 2008 por Paranhos et al. (2016), mesmo após a crise da economia brasileira a partir de 2011.

A metodologia adotada é um estudo de caso sobre as capacidades tecnológicas do Grupo FarmaBrasil, Grupo de empresas nacionais que vem se destacando em suas estratégias inovativas no conjunto das empresas inovadoras. Este estudo traz uma contribuição inédita, pois terá como base uma tabulação especial com dados ainda não publicados da Pesquisa de Inovação (PINTEC), fornecida pelo Instituto Brasileiro de Geografia e Estatística (IBGE). A análise da tabulação irá comparar os dados das empresas do Grupo com os da fabricação de produtos farmoquímicos e farmacêuticos, indústria de transformação e indústria total. Adicionalmente foram coletadas informações quantitativas sobre a evolução e o desempenho industrial da indústria farmacêutica em dados secundários do Anuário da Câmara de Regulação de Medicamentos (CMED). As informações qualitativas sobre o Grupo e suas empresas foram coletadas através de entrevistas telefônicas, no segundo semestre de 2018, e sites das mesmas.

O artigo está organizado em três seções, além da introdução e da conclusão: a primeira discute a situação da indústria farmacêutica no país, mais especificamente sua estrutura de oferta e posicionamento na economia; a segunda seção aborda uma discussão mais teórica acerca das capacidades tecnológicas, servindo como referencial para a discussão dos resultados da análise comparativa da tabulação especial, apresentados na terceira seção. A terceira seção tem duas subseções: na primeira são trazidas informações qualitativas sobre o Grupo FarmaBrasil e na segunda a análise da tabulação especial com os dados agregados das empresas do Grupo em perspectiva com os dados da indústria farmacêutica, indústria de transformação e indústria total.

\section{Atual estrutura de oferta da indústria farmacêutica brasileira}

De acordo com o Guia 2017 da Interfarma, o mercado farmacêutico brasileiro é o $8^{\circ}$ maior no mundo, com a previsão de chegar à $5^{a}$ posição já em 2021. Seu faturamento atingiu a soma de R\$ 85,35 bilhões em 2017. Além disso, o mercado é dividido entre o varejo, responsável por $59 \%$ das vendas, e o mercado institucional, que representa os $41 \%$ restantes. Esse mercado institucional é dividido entre vendas para o governo $(52 \%)$, hospitais $(25 \%)$, clínicas $(11 \%)$ e outras instituições $(12 \%)$.

\footnotetext{
${ }^{1}$ Ver em https://www.nexojornal.com.br/expresso/2017/09/17/Quanto-a-popula\%C3\%A7\%C3\%A3o-brasileira$\mathrm{j} \% \mathrm{C} 3 \% \mathrm{~A} 1$-perdeu-com-a-crise-econ $\% \mathrm{C} 3 \% \mathrm{~B} 4$ mica
} 
O Anuário da CMED indica um crescimento médio nominal do faturamento das empresas farmacêuticas de $15 \%$ de 2014 para 2015, já o crescimento médio real (corrigido pelo IPCA) foi de $6,1 \%$ no mesmo período. Sendo assim, o crescimento do mercado farmacêutico tem sido bem consistente na economia nacional, ainda mais se levado em consideração que a economia como um todo enfrentou um período de recessão no biênio citado, com decréscimo médio real de 3,5\% ao ano.

A política de medicamentos genéricos foi bem-sucedida em termos de escala de produção e distribuição, ajudando algumas empresas nacionais a figurarem entre as maiores no mercado nacional e entre estas estão as empresas do Grupo FarmaBrasil, estudo de caso do artigo. As empresas associadas ao Grupo são 12: Aché, Biolab, Biomm, Bionovis, Blanver, Cristália, EMS, Eurofarma, Hebron, Libbs, Orygen e ReceptaBio. Elas respondem por 25\% das unidades vendidas no mercado brasileiro e quatro estão entre as maiores 10 empresas farmacêuticas que atuam no país, e oito entre as 30 maiores. A Orygen é uma joint venture da Biolab com a Eurofarma e a Bionovis da Aché, EMS, Hypera Pharma e União Química; ambas são produtoras de medicamentos biotecnológicos. A Hebron produz fitoterápicos. A ReceptaBio é uma empresa de P\&D para medicamentos biotecnológicos. A Tabela 1 abaixo traz características das empresas associadas ao Grupo e sua posição no mercado nacional.

Tabela 1 - Empresas associadas ao Grupo FarmaBrasil por faturamento, 2016

\begin{tabular}{c|c|c|c|c|c|c}
\hline Empresa & $\begin{array}{c}\text { Posição no } \\
\text { mercado } \\
\text { nacional }\end{array}$ & $\begin{array}{c}\text { Faturamento } \\
\text { (R\$bilhões) }\end{array}$ & Produtos & $\begin{array}{c}\text { Apresentações } \\
\text { cadastradas } \\
\text { com } \\
\text { comercializaçã } \\
\text { o }\end{array}$ & $\begin{array}{c}\text { Princípios } \\
\text { ativos e } \\
\text { associaçõe } \\
\text { s }\end{array}$ & $\begin{array}{c}\text { Subclasses } \\
\text { terapêutic } \\
\text { a }\end{array}$ \\
\hline SEM & 3 & $>=2$ & 970 & 1938 & 328 & 143 \\
\hline $\begin{array}{c}\text { Hypera } \\
\text { Pharma }\end{array}$ & 5 & $>=2$ & 375 & 656 & 232 & 115 \\
\hline Aché & 6 & $>=2$ & 264 & 610 & 207 & 118 \\
\hline Eurofarma & 7 & $>=2$ & 231 & 506 & 162 & 105 \\
\hline Cristália & 15 & Entre 1 e 2 & 137 & 312 & 131 & 63 \\
\hline Libbs & 18 & Entre 1 e 2 & 71 & 163 & 68 & 50 \\
\hline Biolab & 22 & Entre 0,5 e 1 & 56 & 136 & 55 & 44 \\
\hline $\begin{array}{c}\text { União } \\
\text { Química }\end{array}$ & 29 & Entre 0,5 e 1 & 157 & 255 & 146 & 86 \\
\hline
\end{tabular}

Fonte: Elaboração própria a partir da CMED (2017)

Contudo, a especialização em genéricos pode se tornar uma estratégia arriscada devido à queda generalizada dos preços depois de sua introdução no mercado. Vondeling et al. (2018), após realizarem uma revisão na literatura sobre o impacto da expiração das patentes nos preços dos medicamentos, sugerem que a entrada dos genéricos provoca uma concorrência significativa de preços, embora a extensão em que os preços dos medicamentos diminuem seja diferente entre estudos e países, variando de $6,6 \%$ a $66 \%$ após 1 a 5 anos após a entrada inicial do genérico.

Como visto na introdução, a oferta doméstica de medicamentos genéricos cresceu rapidamente, permitindo o aumento das parcelas de mercado das empresas nacionais, apoiada pela importação de insumos, consequentemente afetando o déficit comercial setorial. Além disso, outro aspecto da oferta doméstica foi que as multinacionais cada vez mais importam produtos finais para comercialização no Brasil, reduzindo suas atividades produtivas no país, 
especialmente as de maior complexidade. (CALIARI; RUIZ, 2013). O crescimento vigoroso do mercado farmacêutico brasileiro não tem sido atendido pela oferta doméstica, mas majoritariamente pela importação de insumos farmacêuticos e de medicamentos com maior tecnologia agregada, e consequentemente de maior valor.

Este cenário da estrutura da indústria reforça a importância das empresas nacionais se capacitarem tecnologicamente a fim de suprir a crescente demanda por novos medicamentos, mais complexos e originários da biotecnologia, paradigma distinto da síntese química.

\section{Referencial para indicadores de acumulação tecnológica}

O catch-up tecnológico significa o estreitamento de lacunas entre as capacidades tecnológicas de firmas e indústrias de economias emergentes em relação às líderes globais. As capacidades tecnológicas, por sua vez, são entendidas como o estoque de recursos necessários para realizar atividades de produção e inovação em diferentes níveis, incluindo habilidades, conhecimentos, experiências e estruturas institucionais. Segundo Bell e Pavitt (1993), apenas o learning by doing e using, realizados na operação das capacidades produtivas, são insuficientes para garantir acumulação tecnológica. Esta é obtida através de ações deliberadas das empresas em atividades endógenas de learning by searching $\mathrm{e}$ interacting.

A inovação pode ser entendida como um processo de conversão de invenções, ideias e conhecimentos tecnológicos ou não tecnológicos em novos produtos, serviços e processos para gerar retornos econômicos e se trata de um processo evolutivo e recursivo de iteração e feedback entre agentes econômicos (HASENCLEVER, 1998; HASENCLEVER, 2013). Contudo, medir a inovação não é algo trivial, embora ela seja considerada o motor do crescimento econômico.

Indicadores são meios utilizados para se obter informações quantitativas sobre certos aspectos de um fenômeno. Porém, não há indicadores perfeitos ou completos, principalmente em se tratando do fenômeno inovação, assim como não há indicadores perfeitos de outros fenômenos socioeconômicos. O problema particular com o fenômeno da inovação é a sua natureza multidimensional, envolvendo mudanças qualitativas nos fatores econômicos, estratégicos, organizacionais e institucionais. Dessa forma, os indicadores capturam apenas parcialmente alguns aspectos do objeto em questão. Portanto, é preciso estar ciente das limitações intrínsecas de um indicador, que não é uma medida objetiva, direta e completa, mas apenas uma aproximação do fenômeno em estudo (MENDONÇA et al., 2004).

Os gastos com P\&D são frequentemente usadas como indicadores de insumo para inovação ou progresso tecnológico. No entanto, a despesa é um insumo para $\mathrm{P} \& \mathrm{D}$, em vez de um resultado, que é a inovação. Outra possibilidade seria usar um indicador produtividade total dos fatores, que é afetada por outros fatores além da inovação e tem problemas de mensuração. As patentes, que podem ser um insumo e um produto do processo de inovação, vêm sendo cada vez mais usadas para mensurá-lo. (NAGAOKA et al., 2010)

É preciso lembrar que as estatísticas de patentes são mais apropriadas como indicadores de atividades inventivas, mas deve-se notar que nem todas as invenções são patenteadas. De fato, no setor farmacêutico, o número de patentes que não são usadas internamente ou licenciadas para outras empresas chega a 63\%. Soma-se ao fato de que neste setor, os investimentos em P\&D levam por volta de 10 a 15 anos para que um novo medicamento seja introduzido no mercado. Portanto, há um número substancial de patentes, ainda em processo de desenvolvimento para se chegar a um medicamento que ainda não 
podem ser lançadas como a inovação no mercado. (NAGAOKA et al., 2010). Sendo assim, as patentes não representam inovação propriamente dita, mas a literatura as caracteriza apenas como proxy da medida de inovação, não estando isentas de problemas e nem correspondendo perfeitamente à inovação.

Desse modo, supõe-se que o patenteamento seja um indicador de esforço inventivo, ou seja, um indicador das capacidades tecnológicas da empresa. De maneira geral, quando for inédito o conhecimento envolvido na invenção, há uma grande probabilidade de ele ser protegido por patente, ou seja, ela representaria um grau de novidade maior do que outras inovações não patenteadas.

De forma geral as métricas para mensurar a inovação seguem o Manual de Oslo (2005). Este é também o caso da PINTEC que é realizada por amostragem probabilística, com periodicidade trienal e abrangência geográfica nacional. Por meio desta pesquisa, faz-se um levantamento de informações para a construção de indicadores setoriais, nacionais e regionais sobre as atividades de inovação empreendidas pelas empresas brasileiras com 10 ou mais pessoas ocupadas. Seu objetivo é a identificação dos fatores que influenciam o comportamento inovador das empresas, detectando e medindo as estratégias, esforços e resultados alcançados por eles. Os períodos de referência utilizados neste artigo são, respectivamente, em cada ano da publicação da pesquisa: 2008: 2006 a 2008; 2011: 2009 a 2011; 2014: 2012 a 2014.

As variáveis da PINTEC analisadas neste artigo são: (i) número de empresas que realizam atividades inovativas; (ii) inovações de produto e/ou processo implementadas; (iii) tipos de atividades inovativas desenvolvidas; (iv) gastos com estas atividades; (v) continuidade das atividades internas de P\&D e número, nível de qualificação e tempo de dedicação das pessoas envolvidas com esta atividade; e (vi) arranjos cooperativos estabelecidos com outra(s) organização(ões).

\section{Os resultados do estudo de caso}

\subsection{Caracterização do Grupo FarmaBrasil}

As empresas associadas do Grupo FarmaBrasil têm como receita líquida de vendas valores que variam entre valores próximos a $R \$ 1$ bilhão e um pouco mais de $R \$ 3$ bilhões no ano de 2016, como apresentado na Tabela 1. Por outro lado, os gastos médios dessas empresas com P\&D variam entre aproximadamente 6 a $10 \%$ de sua receita. Além disso, a grande maioria de suas empresas destina parcela de sua produção para a exportação, o que serve de indicador inicial de competitividade internacional de seus produtos.

As informações qualitativas a seguir são derivadas dos sites das empresas do Grupo e das entrevistas telefônicas, conforme informado na introdução. A estratégia de capacitação tecnológica do Grupo envolve contratação de atividades externas de P\&D junto a parcerias nacionais e internacionais há mais de cinco anos e atividades internas de P\&D com diversos projetos pipelines de medicamentos, divididos em inovação incremental e inovação radical. Além disso, essas empresas investem em pessoal, através de, por exemplo: política de tempo de trabalho, subsídios para cursos, Master Business Administration dentro da empresa, entre outros. Por fim, grande parte dessas empresas possuem também projetos de inovação financiados por organizações governamentais como o Banco Nacional de Desenvolvimento Econômico e Social (BNDES) e a Financiadora de Estudos e Projetos (FINEP).

Um importante indicador inicial das capacidades tecnológicas dessas empresas farmacêuticas seria observar a sua atuação na área de biotecnologia, área que implica um 
esforço tecnológico substancial por ser uma área nova e distinta da síntese química, base tecnológica da produção de genéricos. O Grupo FarmaBrasil já atua no ramo de biotecnologia, contudo, o total da produção e receita advindo desse tipo medicamento ainda é relativamente muito baixo, principalmente quando comparado com o segmento de genéricos. Com a exceção das joint ventures de biotecnologia (Orygen e Bionovis), que são especializadas na produção de biotecnológicos.

Outra característica relevante desse conjunto de empresas para sua capacitação tecnológica é a aquisição de empresas em outros países, principalmente América Latina nos últimos anos, e prospectam o investimento em outras empresas estrangeiras. Além disso, realizam licenciamento de tecnologia de terceiros e o co-desenvolvimento de medicamentos a partir de parcerias com outras empresas nacionais e estrangeiras, e também através de parcerias com universidades e institutos de ciência e tecnologia, inclusive possuindo centros de pesquisa em outros países. Além disso, como será corroborado com os dados quantitativos apresentados na próxima seção, essas empresas alocam cerca de $6 \%$ em atividades de P\&D, sendo $15 \%$ a $20 \%$ dos dispêndios em pesquisa com atividades externas de P\&D. Por fim, o grupo também realiza a produção de medicamentos fitoterápicos, com base no aproveitamento da biodiversidade, com valor aproximado da $\mathrm{R} \$ 120$ milhões em receita líquida de vendas anuais nesse tipo de produto.

O Grupo agrega ainda uma empresa de pesquisa em sua associação. Esse fato demonstra também a importância das associações externas e colaborativas em P\&D. A ReceptaBio, empresa voltada para pesquisa em biotecnologia, é responsável pela geração de linhagens e desenvolvimento de anticorpos monoclonais para uso clínico e descoberta e pesquisa de peptídeos para uso clínico no tratamento de diversos tipos de câncer. A empresa capta recursos de forma não convencional (ou seja, através da venda de produtos), mas sim dos resultados de projetos de pesquisa. Além disso, naturalmente por se tratar de uma empresa de pesquisa, grande parte de sua receita é alocada para as atividades internas de P\&D. Ou seja, esse fato é bastante interessante por mostrar que o Grupo tem investido em iniciativas para novas áreas de pesquisa. Ainda que a empresa seja ainda pequena (R\$ 4 milhões de receita em 2017) é uma empresa especializada em P\&D.

Essa empresa possui seis patentes de produtos, sendo duas patentes derivadas de outra patente. Dessa forma, a empresa possui cinco produtos patenteados, tendo um produto três dessas patentes, outro produto com duas patentes, e um terceiro e quarto com uma patente cada. O quinto produto dessa empresa possui duas patentes no Brasil, duas patentes nos EUA, uma patente na Colômbia e uma patente no Japão. Por fim, ela possui uma patente licenciada por uma empresa dos EUA (Verzani) - a $1^{\text {a }}$ patente brasileira licenciada por uma empresa estrangeira.

Em suma, a caracterização inicial do Grupo indica que suas empresas têm posição de destaque no cenário da indústria farmacêutica nacional. $\mathrm{O}$ grande porte de suas empresas, assim como maiores percentuais relativos de suas receitas voltados para pesquisa (em relação à média brasileira), assim como a atuação em biotecnologia e a forte atuação internacional (seja através da exportação, produção em outros países e parcerias internacionais) já seriam argumentos para uma pesquisa mais minuciosa do tipo de atuação e estratégia dessas empresas em termo de suas capacidades tecnológicas.

Sendo assim, buscou-se observar em que medida essas empresas do estudo de caso aumentaram os seus esforços de inovação e melhoraram o seu posicionamento no mercado através da introdução de inovações e patentes mesmo frente à perda de dinamismo da economia brasileira desde 2011 e crise de 2015. 


\subsection{Análise da tabulação especial da PINTEC}

Como dito anteriormente na introdução e na seção dois, solicitou-se uma tabulação especial, junto ao IBGE, das últimas três edições da PINTEC, com os dados agregados para nove empresas associadas ao Grupo do estudo de caso. Vale ressaltar que, por se tratar de uma pesquisa amostral, o número de empresas que participaram das três pesquisas em cada resposta, pode ser distinto (ver Tabela 4). A análise dos dados do Grupo foi comparativa com o conjunto total da indústria, o conjunto de empresas da indústria de transformação e o conjunto de empresas do setor farmacêutico e farmoquímico.

O número de empresas que inovaram e que constituem a base de dados sobre a qual será elaborada a análise é apresentado na Tabela 4. Para melhor visualização dos dados resolveu-se nomear os agregados de empresas da seguinte forma: Agregado 1 - empresas do Grupo FarmaBrasil; Agregado 2 - empresas de fabricação de produtos farmacêuticos e farmoquímicos; Agregado 3 - empresas da indústria de transformação; Agregado 4 empresas da indústria total.

Tabela 2 - Número de empresas inovadoras em cada agregado e percentual do total, 2008, 2011 e 2014

\begin{tabular}{c|c|c|c|c}
\hline $\begin{array}{c}\text { Ano } \\
\text { PINTEC }\end{array}$ & Agregado & $\begin{array}{c}\mathrm{N}^{\mathbf{d}} \text { de } \\
\text { empresas na } \\
\text { pesquisa (1) }\end{array}$ & $\begin{array}{c}\mathrm{N}^{\mathrm{o}} \text { de empresas } \\
\text { que inovaram } \\
(2)\end{array}$ & $\begin{array}{c}(1) /(2) \\
(\%)\end{array}$ \\
\hline \multirow{4}{*}{2008} & 1 & 9 & 8 & 88,9 \\
\cline { 2 - 5 } & 2 & 495 & 301 & 60,7 \\
\cline { 2 - 5 } & 3 & 9.8420 & 30.291 & 30,8 \\
\cline { 2 - 5 } & 4 & 106.862 & 33.034 & 30,9 \\
\hline \multirow{4}{*}{2011} & 1 & 8 & 8 & 100,0 \\
\cline { 2 - 5 } & 2 & 458 & 211 & 46,1 \\
\cline { 2 - 5 } & 3 & 114.212 & 32.250 & 28,2 \\
\hline \multirow{4}{*}{2014} & 4 & 128.699 & 36.506 & 28,4 \\
\cline { 2 - 5 } & 1 & 8 & 7 & 87,5 \\
\cline { 2 - 5 } & 2 & 406 & 191 & 47,1 \\
\cline { 2 - 5 } & 3 & 115.268 & 33.573 & 29,1 \\
\hline
\end{tabular}

Fonte: Elaboração própria baseada na tabulação especial da PINTEC - IBGE

Como pode ser observado, as empresas do estudo de caso apresentam um perfil diferenciado em relação às atividades inovativas, como já abordado anteriormente. A Tabela 2 informa que as empresas do estudo, em quase sua totalidade, realizaram alguma atividade inovativa nos períodos das pesquisas, enquanto apenas $30 \%$ das empresas da indústria total e de transformação o fizeram. As fabricantes de produtos farmacêuticos e farmoquímicos Agregado 2 - têm um percentual entre $60 \%$ na primeira pesquisa a $47 \%$ na última, o que é compreensível devido ao perfil do setor, mas ainda assim as empresas do Grupo se sobressaem neste quesito mesmo dentro de sua indústria.

A Tabela 3 irá permitir uma melhor visualização do tipo de estratégia adotada por cada agregado, diferenciando assim os esforços de cada um em termos de percentual da receita líquida gasto em atividades internas e externas de $\mathrm{P} \& \mathrm{D}$, aquisição de máquinas e equipamentos e outras atividades inovativas (aquisição de outros conhecimentos externos, treinamento, introdução das inovações tecnológicas no mercado, aquisição de software e 
projeto industrial e outras preparações técnicas) em relação ao total do gasto em atividade inovativa.

Tabela 3 - Tipos de atividades inovativas desenvolvidas em relação a receita líquida por agregado, 2008, 2011 e 2014 (\%)

\begin{tabular}{|c|c|c|c|c|c|c|c|c|}
\hline \multirow[b]{2}{*}{$\begin{array}{l}\text { Ano } \\
\text { Pint- } \\
\text { ec }\end{array}$} & \multirow[b]{2}{*}{$\begin{array}{l}\text { Agre- } \\
\text { gado }\end{array}$} & \multicolumn{5}{|c|}{ Valor em relação a receita líquida (\%) } & \multicolumn{2}{|c|}{$\begin{array}{l}\text { Percentual em } \\
\text { relação ao total do } \\
\text { gasto em atividades } \\
\text { inovativas }(\%)\end{array}$} \\
\hline & & $\begin{array}{l}\text { Total } \\
\text { em } \\
\text { ativida- } \\
\text { des } \\
\text { inovati- } \\
\text { vas }\end{array}$ & $\begin{array}{l}\text { Atividades } \\
\text { internas } \\
\text { de P\&D }\end{array}$ & $\begin{array}{l}\text { Aquisi- } \\
\text { ção } \\
\text { externa } \\
\text { de } \\
\text { P\&D }\end{array}$ & $\begin{array}{l}\text { Aquisição } \\
\text { de } \\
\text { máquinas } \\
\text { e equipa- } \\
\text { mentos }\end{array}$ & $\begin{array}{l}\text { Outras } \\
\text { ativida- } \\
\text { des* }\end{array}$ & $\begin{array}{l}\text { Ativida- } \\
\text { des } \\
\text { internas } \\
\text { de P\&D }\end{array}$ & $\begin{array}{l}\text { Aquisição } \\
\text { de } \\
\text { máquinas } \\
\text { e equipa- } \\
\text { mentos }\end{array}$ \\
\hline \multirow{4}{*}{2008} & 1 & 11,2 & 3,1 & 0,7 & 3,7 & 3,7 & 28,0 & 32,9 \\
\hline & 2 & 4,9 & 1,4 & 0,6 & 1,3 & 1,6 & 29,4 & 25,9 \\
\hline & 3 & 2,6 & 0,6 & 0,1 & 1,3 & 0,6 & 24,6 & 49,1 \\
\hline & 4 & 2,9 & 0,8 & 0,1 & 1,3 & 0,6 & 28,1 & 44,9 \\
\hline \multirow{4}{*}{2011} & 1 & 6,6 & 3,9 & 1,2 & 0,2 & 1,3 & 59,4 & 3,5 \\
\hline & 2 & 4,8 & 2,4 & 0,6 & 0,8 & 1,1 & 49,8 & 15,6 \\
\hline & 3 & 2,5 & 0,7 & 0,1 & 1,2 & 0,5 & 29,4 & 47,1 \\
\hline & 4 & 2,6 & 0,8 & 0,2 & 1,1 & 0,5 & 30,8 & 42,4 \\
\hline \multirow{4}{*}{2014} & 1 & 5,0 & 3,7 & 0,9 & 0,1 & 0,3 & 73,8 & 2,4 \\
\hline & 2 & 4,2 & 2,2 & 0,4 & 0,6 & 0,9 & 53,8 & 15,4 \\
\hline & 3 & 2,2 & 0,7 & 0,2 & 0,9 & 0,4 & 31,4 & 39,8 \\
\hline & 4 & 2,5 & 0,8 & 0,3 & 1,0 & 0,4 & 30,3 & 41,1 \\
\hline
\end{tabular}

*Aquisição de outros conhecimentos externos, treinamento, introdução das inovações tecnológicas no mercado, aquisição de software e projeto industrial e outras preparações técnicas

Fonte: Elaboração própria baseada na tabulação especial da PINTEC - IBGE

A partir da Tabela 3, novas observações e análises mais consistentes podem ser feitas em termos do tipo de atividade inovativa desenvolvida por cada agregado. Em relação ao total investido em atividades inovativas em relação à receita líquida, nas três pesquisas da PINTEC, o patamar realizado pelo agregado 1 é consideravelmente superior aos agregados 3 e 4, e levemente superior ao agregado 2, exceto na pesquisa de 2008.

Pode também ser observado que o total investido em tipos de atividades inovativas em relação à receita líquida do agregado 1 cai ao longo das pesquisas. Contudo, importante observar que o componente que apresenta a maior queda é na participação relativa da aquisição de máquinas e equipamentos, que passa de um total de $32,9 \%$ do total gasto em atividades inovativas, na primeira pesquisa, para apenas $2,4 \%$ na última. Esse movimento não ocorreu de forma alguma com os agregados 3 e 4, que mantiveram o mesmo patamar entre 40 e $50 \%$ do total gasto em atividades inovativas com a aquisição de máquinas e equipamentos. Já o agregado 2, composto pelos fabricantes de produtos farmacêuticos e farmoquímicos, teve um gasto médio relativo inferior, na primeira pesquisa, em relação ao agregado 1, porém manteve o patamar de $15 \%$ nas duas pesquisas seguintes, bem superior ao grupo de empresas do Grupo FarmaBrasil.

Por outro lado, observando os indicadores de atividades internas e aquisição externa de P\&D é que se pode diferenciar melhor o tipo atividade inovativa realizada por cada 
agregado. Enquanto no agregado 1 o percentual gasto em relação à receita líquida nessas duas atividades foi de $3,8 \%$, atingindo a soma de $5,1 \%$ e decrescendo de maneira sutil para $4,6 \%$ na última pesquisa, isso foi longe do observado nos agregados 3 e 4 , e quase o dobro do observado pelo agregado 2 , uma vez que nas empresas da indústria total e da indústria de transformação o patamar de gastos foi mantida e não chegou a ultrapassar $1 \%$ da receita líquida nas três pesquisas. Além disso, enquanto o valor gasto pelos agregados 3 e 4 nas atividades internas de $\mathrm{P} \& \mathrm{D}$ margearam os $30 \%$ dos gastos em atividades inovativas nas três pesquisas, na PINTEC de 2014, a média das empresas do estudo de caso atingiu 73,8\% (levando-se em consideração as atividades externas de P\&D, o percentual dos gastos alcançou $90,7 \%$ nessa pesquisa).

Sendo assim, fica mais nítida a diferença entre as estratégias de inovação dos distintos agregados de empresas consultadas nessa pesquisa. Como já salientado na seção dois, a capacidade de tornar endógenos os processos de inovação, através do learning by searching e interating, é considerada o principal determinante do crescimento e desenvolvimento das empresas e por fim dos países. A partir dos valores representados na Tabela 3, pode-se notar que as empresas do estudo de caso e, em menor grau, as empresas fabricantes de produtos farmacêuticos e farmoquímicos, possuem um maior foco em desenvolver internamente a P\&D necessários para inovar. Dessa forma, essas empresas teriam uma maior preocupação na acumulação de conhecimentos tecnológicos, e principalmente, a visão de ampliar esses conhecimentos e produzir inovações, como mostram seus gastos, nitidamente mais importantes do que a indústria de transformação.

O agregado 1 demonstra de maneira mais sólida que, dado o seu enfoque nas duas últimas pesquisas em atividades internas de $\mathrm{P} \& \mathrm{D}$, esse grupo teria uma produção com maior embasamento na atividade inovativa do que em trocas comerciais e de acumulação de equipamentos e de outros recursos materiais também importantes como insumos da inovação, o que não pode ser observado na média da indústria, que tem como enfoque a compra de bens de capital - inovação incorporada -, dependendo de terceiros para desenvolver suas capacidades produtivas e por fim, sua competitividade.

O percentual de aquisição externa de P\&D também indica que o agregado 1 busca uma maior articulação com instituições externas para a criação de conhecimento visando influenciar de maneira positiva sua acumulação de capacidade tecnológica e aumentando enfim sua base de conhecimentos. Da mesma maneira, em termos relativos, a proporção gasta pela média da indústria é bem menor nesse indicador. Contudo, parte da explicação dessa diferença se deve ao fato do setor farmacêutico como um todo ter como necessidade o aumento de sua especialização e de um conhecimento multidisciplinar. Assim, as parcerias externas teriam uma maior importância natural nas atividades em inovação dessas empresas. Além disso, a biotecnologia, a menor produtividade da síntese química e a busca pela redução de custos e riscos também geram o maior enfoque nas atividades externas de P\&D.

$\mathrm{Na}$ medida em que investimentos e esforços contínuos em P\&D interna e externa às empresas são mais frequentes quanto maior for o posicionamento ofensivo das empresas em relação a seus concorrentes, maior é a relevância desses indicadores e da observação dos mesmos dentre as empresas do estudo de caso, demonstrando que, ao menos em relação à média da indústria brasileira, esse conjunto de empresas apresenta uma estratégia diferenciada e, de acordo com a abordagem seguida nesse artigo, mais efetiva para alcançar maiores níveis de capacidades tecnológicas.

Esses resultados tornam mais claro que apenas a aquisição de tecnologia no exterior não substitui os esforços internos. Ao contrário, é necessário muito conhecimento para poder 
interpretar a informação, selecionar, comprar (ou copiar), transformar e internalizar a tecnologia importada.

Estes resultados corroboram a evolução das capacidades tecnológicas ds empresas associadas ao Grupo FarmaBrasil, já que elas dão maior importância à capacitação interna frente à incorporação de tecnologia e sua superioridade em relação à mera importação de tecnologia do exterior, muitas vezes incorporada em máquinas e equipamentos.

Tabela 4 - Proporção dos tipos de inovação realizados por agregado em relação ao total de empresas pesquisadas por períodos $(\%)$

\begin{tabular}{|c|c|c|c|c|c|c|}
\hline $\begin{array}{l}\text { Período } \\
\text { PINTEC }\end{array}$ & Agregado & $\begin{array}{c}\text { Inovação } \\
\text { de produto } \\
\text { e/ou } \\
\text { processo }\end{array}$ & $\begin{array}{l}\text { Inovação } \\
\text { de } \\
\text { produto e } \\
\text { processo }\end{array}$ & $\begin{array}{l}\text { Inovação } \\
\text { de } \\
\text { produto }\end{array}$ & $\begin{array}{c}\text { Inovação } \\
\text { de } \\
\text { processo }\end{array}$ & $\begin{array}{c}\text { Apenas } \\
\text { inovações } \\
\text { organizacionais } \\
\text { e/ou de } \\
\text { marketing } \\
\end{array}$ \\
\hline \multirow{4}{*}{$\begin{array}{l}2006- \\
2008\end{array}$} & 1 & 88,9 & 77,8 & 88,9 & 77,8 & 11,1 \\
\hline & 2 & 63,7 & 27,7 & 47,6 & 43,8 & 21,2 \\
\hline & 3 & 38,4 & 17,0 & 23,1 & 32,3 & 35,0 \\
\hline & 4 & 38,6 & 17,2 & 23,7 & 32,1 & 34,8 \\
\hline \multirow{4}{*}{$\begin{array}{l}2009- \\
2011\end{array}$} & 1 & 100,0 & 100,0 & 100,0 & 100,0 & 0,0 \\
\hline & 2 & 53,8 & 20,5 & 37,0 & 37,4 & 31,5 \\
\hline & 3 & 35,9 & 13,5 & 17,5 & 32,0 & 35,2 \\
\hline & 4 & 35,7 & 14,1 & 18,1 & 31,7 & 34,9 \\
\hline \multirow{4}{*}{$\begin{array}{l}2012- \\
2014\end{array}$} & 1 & 87,5 & 75,0 & 87,5 & 75,0 & 0,0 \\
\hline & 2 & 52,2 & 31,7 & 39,0 & 44,8 & 24,4 \\
\hline & 3 & 36,3 & 14,5 & 18,4 & 32,5 & 34,1 \\
\hline & 4 & 36,0 & 14,6 & 18,5 & 32,1 & 33,7 \\
\hline
\end{tabular}

Fonte: Elaboração própria baseada na tabulação especial da PINTEC - IBGE

A partir dos dados apresentados na Tabela 4, novas conclusões podem ser elaboradas que reforçam a visão de uma estratégia diferenciada de inovação do grupo de empresas do estudo de caso. Em relação à média das empresas pesquisadas, o agregado 1 possui percentuais bem superiores em inovação de produtos ou processo comparado à média da indústria como um todo, e também em relação à indústria farmacêutica e farmoquímica. Enquanto a grande maioria das empresas do agregado 1 realizaram inovações de produtos e processo, principalmente em produtos, uma parcela significante dos outros agregados realizou em maior percentual inovações organizacionais e/ou de marketing. Essa constatação reforça que, dado o perfil dos gastos em atividades inovativas, o resultado mais favorável em relação ao tipo de inovação reforça a importância das atividades internas de P\&D (de preferência combinada a atividades externas de P\&D).

Tabela 5 - Proporção do grau de novidade da inovação por agregado em relação às inovações geradas por agregado de empresas $(\%)$

\begin{tabular}{c|c|c|c|c|c}
\hline Período & Agregado & $\begin{array}{c}\text { Produto } \\
\text { novo para } \\
\text { o } \\
\text { mercado } \\
\text { nacional }\end{array}$ & $\begin{array}{c}\text { Produto } \\
\text { novo para o } \\
\text { mercado } \\
\text { mundial }\end{array}$ & $\begin{array}{c}\text { Processo } \\
\text { novo para o } \\
\text { mercado } \\
\text { nacional }\end{array}$ & $\begin{array}{c}\text { Processo } \\
\text { novo em } \\
\text { termos } \\
\text { mundiais }\end{array}$ \\
\hline $\begin{array}{c}2006- \\
2008\end{array}$ & 1 & 44,4 & 22,2 & 22,2 & 11,1 \\
\cline { 2 - 6 } & 2 & 16,7 & 2,9 & 3,8 & 0,2 \\
\hline
\end{tabular}




\begin{tabular}{c|c|c|c|c|c}
\hline & 3 & 4,2 & 0,3 & 2,3 & 0,1 \\
\cline { 2 - 6 } & 4 & 4,4 & 0,3 & 2,4 & 0,1 \\
\hline \multirow{3}{*}{$2009-$} & 1 & 75,0 & 12,5 & 12,5 & 0,0 \\
\cline { 2 - 6 } 2011 & 2 & 20,0 & 2,8 & 7,5 & 0,7 \\
\cline { 2 - 6 } & 3 & 3,6 & 0,4 & 2,2 & 0,2 \\
\hline \multirow{3}{*}{$2012-$} & 4 & 4,1 & 0,4 & 2,4 & 0,2 \\
\cline { 2 - 6 } 2014 & 1 & 37,5 & 12,5 & 37,5 & 0,0 \\
\cline { 2 - 6 } & 3 & 11,3 & 3,0 & 6,7 & 0,0 \\
\cline { 2 - 6 } & 4 & 3,8 & 0,4 & 2,6 & 0,3 \\
\hline
\end{tabular}

Fonte: Elaboração própria baseada na tabulação especial da PINTEC

A Tabela 5 traz informação sobre o quanto a inovação realizada por agregado teve o potencial de ser tornar um diferencial competitivo. Ou seja, dado que uma inovação é o único processo capaz de assegurar o catching-up tecnológico, apenas o investimento contínuo em atividades de P\&D com uma busca deliberada de capacitação tecnológica para inovar irá gerar resultados competitivos positivos.

Como mostrado na Tabela 5, o agregado 1 do estudo de caso teve um resultado bem superior em relação ao grau de novidade de suas inovações em relação à média da indústria. Suas inovações em relação ao mercado nacional tiveram um comportamento destacado, sendo produtos novos para esse mercado em grande parte das vezes, atingindo $75 \%$ de suas inovações de produto novas também para o mercado brasileiro. Outro indicador ainda mais consistente para sinalizar o catching up tecnológico são as inovações em nível mundial, cujos indicadores relativos ao estudo de caso tiveram um desempenho bem superior em relação à média da indústria brasileira. Os indicadores de processo também sinalizam o desempenho superior do agregado 1 em relação aos demais agregados, especialmente aos agregados 3 e 4 , contudo, o percentual é menos significante frente aos índices relativos às inovações de produto.

Por outro lado, percebe-se também um ponto adverso nesses indicadores de grau de novidade da inovação, se a evolução do agregado 1 for isolada dos outros agregados. Enquanto na PINTEC de 2008 há um percentual de inovações de nível mundial mais significativo, ele cai para a metade nas duas pesquisas seguintes. Apesar também do aumento de inovações de nível nacional na pesquisa seguinte, esse indicador tem uma forte queda na PINTEC de 2014. Além disso, pode-se notar que esse perfil de mudança não ocorre com os outros agregados ao longo das pesquisas.

Algumas outras explicações podem ser realizadas a partir desses dados. A inovação em nível mundial mais consistente na pesquisa de 2008 pode ter sido fruto da maior oferta de políticas públicas voltadas para a indústria farmacêutica na primeira década dos anos 2000 , como levantado no segundo capítulo. Já a queda das inovações em nível nacional da pesquisa de 2011 para a de 2014 pode ser explicada pela conjuntura econômica adversa do país nesse ínterim, que seria ainda aprofundada nos anos seguintes, como já ressaltado. Uma vez que a inovação envolve riscos e incertezas, especialmente em projetos tecnologicamente mais sofisticados, que irão determinar o grau de novidade dessa inovação, em um momento de crise as empresas naturalmente se tornam mais avessas ao risco devido à incerteza do cenário econômico. Dessa forma, elas direcionam suas pesquisas para inovações de natureza mais incremental e menos radical, o que, por fim, pode explicar a maior proporção das inovações do agregado 1 na PINTEC de 2014 apenas ao nível da empresa. 
Um fator externo e comum à indústria farmacêutica em todos os países, que também pode ter causado impacto no número de inovações de classe mundial, é o aumento da complexidade das inovações farmacêuticas. As técnicas de descoberta de medicamentos avançaram significativamente devido a grandes desenvolvimentos em biologia, engenharia genética, enzimologia e bioinformática. Assim, há um maior esforço necessário para a descoberta de novos medicamentos realmente inovadores. $\mathrm{O}$ que condiz com o fato de haver uma queda no ritmo de descoberta de novas entidades moleculares, apesar do aumento exponencial de gastos com P\&D (DEMIREL; MAZZUCATO, 2012).

Uma importante característica da inovação é que ela é um processo cumulativo e não um evento isolado e casual. Dessa forma, as atividades internas de P\&D devem ser realizadas de maneira contínua, fato ainda mais relevante na medida em que isso permitirá uma crescente incorporação de conhecimentos nas atividades produtivas. Portanto, os resultados diferentes em relação ao grau de novidade e frequência das inovações podem ser também explicados pela proporção de tipos de gastos das atividades inovativas apresentados na Tabela 4 e pela continuidade temporal apresentada na Tabela 6.

Tabela 6 - Proporção da continuidade temporal dos gastos em atividades inovativas internas em relação ao total de atividades internas (\%)

\begin{tabular}{c|c|c|c|c|c}
\hline $\begin{array}{c}\text { Ano } \\
\text { PINTEC }\end{array}$ & Agregado & $\begin{array}{c}\text { Atividades } \\
\text { contínuas }\end{array}$ & $\begin{array}{c}\% \\
\text { empresas }\end{array}$ & $\begin{array}{c}\text { Atividades } \\
\text { ocasionais }\end{array}$ & $\begin{array}{c}\% \\
\text { empresas }\end{array}$ \\
\hline \multirow{4}{*}{2008} & 1 & 87,5 & 100,0 & 12,5 & - \\
\cline { 2 - 6 } & 2 & 72,5 & 97,5 & 27,5 & 2,5 \\
\cline { 2 - 6 } & 3 & 72,0 & 96,8 & 28,0 & 3,2 \\
\cline { 2 - 6 } & 4 & 77,7 & 91,0 & 22,3 & 9,0 \\
\hline \multirow{4}{*}{2011} & 1 & 100,0 & 100,0 & - & - \\
\cline { 2 - 6 } & 2 & 75,6 & 97,8 & 24,4 & 2,2 \\
\cline { 2 - 6 } & 3 & 73,0 & 97,8 & 27,0 & 2,2 \\
\cline { 2 - 6 } & 4 & 89,7 & 99,5 & 10,3 & 0,5 \\
\cline { 2 - 6 } 2014 & 1 & 100,0 & 100,0 & - & - \\
\cline { 2 - 6 } & 2 & 74,1 & 97,0 & 25,9 & 3,0 \\
\cline { 2 - 6 } & 3 & 72,5 & 96,9 & 27,5 & 3,1 \\
\hline
\end{tabular}

Fonte: Elaboração própria baseada na tabulação especial da PINTEC- IBGE

Como pode ser observado na Tabela 6 , o caráter das atividades internas pode ser divido entre gastos contínuos ou gastos ocasionais. Os gastos em atividades de P\&D no país, como indicado pelos percentuais da Tabela 6, são realizados majoritariamente de forma contínua. Porém, há uma diferença entre os agregados que podem ser explicados da seguinte maneira: enquanto as empresas dos agregados 1 e 2 tem um determinado perfil de atividades que demanda uma contínua atualização e incorporação de novos conhecimentos em suas atividades produtivas, o mesmo não pode ser dito pelo conjunto de empresas da indústria, onde o padrão de concorrência parece não ser predominantemente a partir da introdução de inovações como é o caso da indústria farmacêutica. Vale também ressaltar a importância do learning by search e interacting nas próprias atividades inovativas, de maneira que uma atividade realizada de maneira contínua ao longo do tempo tende a criar rotinas que tornam a atividade mais eficiente e ter melhores resultados concretos se comparado a atividades de pesquisa realizadas de maneira esporádica. 
As empresas que compõe os agregados 3 e 4 realizam atividades internas de P\&D de maneira ocasional de maneira mais significativa, sendo que os percentuais médios gastos em relação ao número de empresas que as realizam é bem superior à média das atividades internas contínuas nesse agregado, o que pode ser explicado por eventuais grandes projetos de inovação que, uma vez realizados, colocam a empresa em um patamar superior e não exige novos esforços de P\&D.

Tabela 7 - Proporção do principal responsável pelo desenvolvimento da inovação entre as empresas que implementaram inovações de produto e de processo (\%)

\begin{tabular}{|c|c|c|c|c|c|c|c|c|c|}
\hline \multirow[b]{2}{*}{$\begin{array}{c}\text { Perío- } \\
\text { do }\end{array}$} & \multirow[b]{2}{*}{$\begin{array}{l}\text { Agre- } \\
\text { gado }\end{array}$} & \multicolumn{4}{|c|}{ Produto } & \multicolumn{4}{|c|}{ Processo } \\
\hline & & $\begin{array}{c}\text { A } \\
\text { em- } \\
\text { presa }\end{array}$ & $\begin{array}{l}\text { Outra } \\
\text { empre- } \\
\text { sa do } \\
\text { grupo }\end{array}$ & $\begin{array}{c}\text { Coopera- } \\
\text { ção com } \\
\text { outros }\end{array}$ & $\begin{array}{c}\text { Outras } \\
\text { empre- } \\
\text { sas ou } \\
\text { institu- } \\
\text { tos }\end{array}$ & $\begin{array}{c}\text { A } \\
\text { em- } \\
\text { presa }\end{array}$ & $\begin{array}{c}\text { Outra } \\
\text { empre- } \\
\text { sa do } \\
\text { grupo }\end{array}$ & $\begin{array}{l}\text { Cooperação } \\
\text { com outros }\end{array}$ & $\begin{array}{c}\text { Outras } \\
\text { empresas } \\
\text { ou } \\
\text { institutos }\end{array}$ \\
\hline \multirow{4}{*}{$\begin{array}{c}2006- \\
2008\end{array}$} & 1 & 62,5 & 0,0 & 12,5 & 25,0 & 0,0 & 0,0 & 28,6 & 71,4 \\
\hline & 2 & 71,3 & 8,9 & 15,2 & 4,6 & 19,5 & 4,1 & 12,3 & 64,1 \\
\hline & 3 & 84,1 & 1,7 & 7,8 & 6,4 & 12,1 & 1,1 & 3,3 & 83,6 \\
\hline & 4 & 84,4 & 1,8 & 7,6 & 6,2 & 12,9 & 1,0 & 3,7 & 82,3 \\
\hline \multirow{4}{*}{$\begin{array}{l}2009- \\
2011\end{array}$} & 1 & 75,0 & 0,0 & 12,5 & 12,5 & 37,5 & 0,0 & 12,5 & 50,0 \\
\hline & 2 & 73,4 & 8,9 & 8,9 & 8,8 & 27,1 & 2,9 & 9,9 & 60,1 \\
\hline & 3 & 83,4 & 1,8 & 5,6 & 9,1 & 16,4 & 0,8 & 6,1 & 76,7 \\
\hline & 4 & 82,6 & 2,1 & 7,1 & 8,2 & 18,4 & 1,0 & 6,7 & 73,9 \\
\hline \multirow{4}{*}{$\begin{array}{l}2012- \\
2014\end{array}$} & 1 & 71,4 & 0,0 & 14,3 & 14,3 & 66,7 & 0,0 & 16,7 & 16,7 \\
\hline & 2 & 78,1 & 1,9 & 8,5 & 11,6 & 27,0 & 1,2 & 5,9 & 65,9 \\
\hline & 3 & 78,5 & 1,9 & 8,3 & 11,3 & 25,9 & 1,2 & 6,0 & 66,8 \\
\hline & 4 & 65,4 & 7,8 & 14,6 & 12,2 & 45,5 & 1,6 & 23,7 & 29,2 \\
\hline
\end{tabular}

Fonte: Elaboração própria baseada na tabulação especial da PINTEC - IBGE

A Tabela 7 permite observar as diferenças proporcionais entre os principais responsáveis pelo desenvolvimento da inovação realizada pelos agregados ao longo das três pesquisas da PINTEC. De maneira geral, os valores são bem próximos entre os agregados e entre as diferentes pesquisas. Uma diferença principal se observa entre os tipos de inovação, pois enquanto as inovações de produto são majoritariamente realizadas pela empresa, as inovações de processo têm como principal responsável outras empresas ou institutos. Por outro lado, percebe-se que as empresas do agregado 1 e 4 possuem, na média, uma maior importância relativa da própria empresa em desenvolver as suas inovações de processo.

Além disso, algumas outras diferenças podem ser notadas. Primeiro, as empresas do agregado 2 têm uma maior participação relativa de empresas do próprio grupo societário como responsável pela inovação, o que pode ser explicado pelo fato das empresas desse grupo terem a maior probabilidade de pertencerem a algum conglomerado econômico ou filial de alguma multinacional, já que esse agregado engloba todas as empresas farmacêutica atuando no país, nacionais e transnacionais.

Segundo, as empresas do agregado 1 e em menor grau, as empresas do agregado 2, têm uma maior participação relativa de outras empresas ou institutos e através de cooperação com outras empresas e institutos como responsáveis por sua inovação de produto, explicado pela complexidade da inovação no setor, necessitando de maneira concomitante a atividade interna, a contratação de $\mathrm{P} \& \mathrm{D}$ externo ou aquisição de tecnologia de maneira direta no caso 
de outras empresas e institutos como responsáveis. Essa mesma linha de raciocínio serve para explicar os casos de cooperação, pois devido à complexidade e multidisciplinaridade das inovações farmacêuticas nos dias de hoje, especialmente em áreas de tecnologia disruptiva e de ponta (por exemplo, a biotecnologia e a nanotecnologia), inovações de maior complexidade dificilmente são realizadas por apenas uma empresa, uma vez que é necessária a interface com uma gama de outros setores e conhecimentos específicos.

Tabela 8 - Número de pessoas ocupadas em P\&D e regime de dedicação de acordo com o agregado de empresas e suas proporções (\%)

\begin{tabular}{|c|c|c|c|c|c|c|c|c|}
\hline \multirow[b]{2}{*}{ Período } & \multirow[b]{2}{*}{ Agregado } & \multirow{2}{*}{$\begin{array}{c}\mathrm{n}^{\mathrm{o}} \mathrm{de} \\
\text { pessoas } \\
\text { ocupadas } \\
(1)\end{array}$} & \multicolumn{6}{|c|}{$n^{\circ}$ de pessoas ocupadas em P\&D } \\
\hline & & & $\begin{array}{c}\text { Dedicação } \\
\text { exclusiva } \\
\text { (2) }\end{array}$ & $\begin{array}{c}(2) /(1) \\
(\%)\end{array}$ & $\begin{array}{l}\text { Dedicação } \\
\text { parcial (3) }\end{array}$ & $\begin{array}{c}(3) /(1) \\
(\%)\end{array}$ & $\begin{array}{c}(2+3) /(1) \\
(\%)\end{array}$ & $\begin{array}{c}(3) /(2) \\
(\%)\end{array}$ \\
\hline \multirow{4}{*}{2008} & 1 & 16.996 & 594 & 3,5 & 12 & 0,1 & 3,6 & 2,0 \\
\hline & 2 & 93.955 & 1.671 & 1,8 & 352 & 0,4 & 2,2 & 21,1 \\
\hline & 3 & 6.852 .023 & 42.942 & 0,6 & 13.119 & 0,2 & 0,8 & 30,6 \\
\hline & 4 & 7.530 .636 & 67.594 & 0,9 & 17.248 & 0,2 & 1,1 & 25,5 \\
\hline \multirow{4}{*}{2011} & 1 & 20.711 & 624 & 3,0 & 10 & 0,0 & 3,1 & 1,6 \\
\hline & 2 & 100.778 & 2.970 & 2,9 & 936 & 0,9 & 3,9 & 31,5 \\
\hline & 3 & 7.598 .170 & 60.399 & 0,8 & 32.466 & 0,4 & 1,2 & 53,8 \\
\hline & 4 & 8.763 .624 & 88.415 & 1,0 & 45.523 & 0,5 & 1,5 & 51,5 \\
\hline \multirow{4}{*}{2014} & 1 & 27.458 & 1.158 & 4,2 & 54 & 0,2 & 4,4 & 4,7 \\
\hline & 2 & 113.890 & 3.145 & 2,8 & 923 & 0,8 & 3,6 & 29,4 \\
\hline & 3 & 7.778 .050 & 60.475 & 0,8 & 38.993 & 0,5 & 1,3 & 64,5 \\
\hline & 4 & 9.094 .054 & 88.329 & 1,0 & 55.495 & 0,6 & 1,6 & 62,8 \\
\hline
\end{tabular}

Fonte: Elaboração própria baseada na tabulação especial da PINTEC - IBGE

A Tabela 8 apresenta outra diferença do perfil das atividades internas de P\&D por agregado. A partir do número relativo de pessoas alocadas em pesquisa dentre o número total de pessoas ocupadas pelo grupo, observa-se uma média que é bem diferente de acordo com os agregados. Primeiramente, observando-se os valores do grupo que é foco do artigo, nota-se que o número de pessoas ocupadas em $\mathrm{P} \& \mathrm{D}$ em relação ao total de pessoas ocupadas é bem superior à média da indústria e também superior à média dos fabricantes de produtos farmacêuticos e farmoquímicos, atingido um total de $4,4 \%$ do pessoal ocupado em pesquisa.

Contudo, o ponto que se percebe o maior destaque está na diferença entre os regimes de dedicação por agregado. Por um lado, enquanto os agregados 3 e 4 possuíam uma média de pessoal com dedicação parcial em P\&D na ordem de 30\% na pesquisa da PINTEC de 2008, esse percentual foi aumentando de maneira contínua nas pesquisas seguintes, ultrapassando a faixa de 50\% na pesquisa de 2011 e finalizando em um valor superior a $60 \%$ na última pesquisa realizada. Já em relação ao grupo de empresas do agregado 1, esse percentual não ultrapassa os $5 \%$ em nenhuma das três pesquisas, atingindo apenas $1,6 \%$ na pesquisa de 2011 . Esse dado demonstra que esse agregado desenvolve de maneira perene suas atividades de $\mathrm{P} \& \mathrm{D}$, na medida em que seus pesquisadores realizam seu trabalho em regime de dedicação exclusiva, o que dá uma dinâmica contínua ao processo de pesquisa necessário à inovação. Sendo assim, pode-se dizer que esse dado também serve para reforçar a hipótese de uma estratégia de inovação diferenciada em relação à média das demais indústrias utilizadas na comparação. 
Dessa forma, na medida em que a busca por inovação se torna essencial para o processo competitivo e a sobrevivência em um mercado aberto e globalizado, especialmente em setor com maior tecnologia agregada, as evidências acima servem de reforço para a hipótese da pesquisa. Ou seja, os dados da tabulação especial reforçam o ponto de vista de que o grupo de empresas do estudo de caso tem buscado a consolidação de seus esforços mediante uma estratégia proativa em inovação, especialmente se comparados à média da indústria farmacêutica brasileira.

\section{Conclusão}

O artigo teve como objetivo avaliar se houve avanço das capacidades tecnológicas das grandes empresas nacionais produtoras de medicamentos, confirmando uma tendência, após inflexão observada a partir de 2008, nos esforços inovativos dessas empresas. Para tanto, optou-se por realizar um estudo de caso de um grupo particular de empresas farmacêuticas de capital nacional, o Grupo FarmaBrasil. Esse Grupo de nove empresas brasileiras tem apresentado, desde 2008, um posicionamento estratégico distinto em relação às atividades inovativas, evoluindo de uma situação de apenas imitadoras para uma posição de inovadoras.

Os resultados do estudo mostraram que o padrão de investimentos em $\mathrm{P} \& \mathrm{D}$ das empresas do Grupo FarmaBrasil em inovação manteve-se com um perfil bastante diferenciado em relação à indústria nacional, assim como, em menor grau, em relação à indústria farmacêutica e farmoquímica no país, mesmo após a crise da economia e da indústria brasileiras. De fato, enquanto na última pesquisa da PINTEC as atividades internas e externas de P\&D do Grupo atingiram $92 \%$ de todos os gastos em atividades inovativas, percentual esse que era de $77 \%$ na pesquisa anterior e apenas 34\% na pesquisa de 2008 , na indústria de transformação esse percentual é pouco expressivo, permanecendo por volta de um terço dos gastos totais nas três pesquisas. Esse percentual é o dobro do investido pela indústria do país em 2014, apesar de já ter sido quase quatro vezes maior na pesquisa de 2008,

Contudo, o resultado mais significativo para responder à pergunta de pesquisa foi a identificação do tipo de estratégia realizada para atingir a inovação. A abordagem adotada na pesquisa enfatiza a importância de tornar endógeno o processo de inovação para acumulação de capacidades tecnológicas, ou seja, que apenas a aquisição de tecnologia externa não substitui os esforços internos. De fato, enquanto as empresas do estudo de caso, além de investirem percentualmente sua receita líquida em atividades inovativas em um patamar bem superior à média da indústria em todas as edições da pesquisa, realizam essas atividades de maneira continuada. Acrescenta-se ainda que a aquisição de bens de capital, que corresponde à tecnologia incorporada em máquinas e equipamentos gerada externamente, esse gasto é relativamente menor em comparação à média da indústria. Nesta a aquisição de bens de capital representa a metade dos gastos de inovação da indústria, enquanto nas empresas do Grupo FarmaBrasil estes representam um papel marginal de aproximadamente 3\% nas duas últimas pesquisas.

O que foi realizado pelas empresas do estudo de caso demonstra, dessa forma, a trajetória distinta em capacitação tecnológica, e vem confirmar a suposição inicial do artigo de que esse Grupo, além de se destacar das demais empresas, não sofreu uma inflexão negativa após a crise da economia brasileira iniciada em 2011 e piorada em 2015. Apesar de que a partir dos dados da PINTEC se percebe um menor volume total destinado às atividades inovativas, as atividades tidas como as mais relevantes para uma criação endógena de conhecimento foram preservadas. Os percentuais da receita líquida em atividades inovativas do estudo de caso caíram expressivamente desde 2008, saindo de um patamar de $11,2 \%$ e atingindo menos da metade em 2014, totalizando apenas $5 \%$ de sua receita líquida, o que 
ainda é muito superior ao gasto pelas empresas das indústrias farmoquímica e farmacêutica e da indústria de transformação.

Além disso, em relação aos dados relativos ao nível de novidade das inovações apresentadas pelas empresas do estudo de caso, há uma queda perceptível das inovações de nível mundial após a pesquisa de 2008 e uma queda bem acentuada das inovações de nível nacional na pesquisa PINTEC de 2014. Esse dado pode refletir um comportamento menos agressivo e avesso ao risco na inovação por parte dessas empresas, dada a conjuntura no período. Vale também ressaltar que o período em que a crise econômica foi mais acentuada, o biênio de 2015 e 2016, junto à fraca recuperação dos dois anos seguintes, não foi contemplado nos dados da PINTEC coletados junto ao IBGE. A próxima edição da PINTEC, portanto, será interessante para as pesquisas futuras chegarem a um resultado mais concreto em relação à possíveis impactos da desaceleração econômica nas atividades e esforços inovativos dessas empresas.

O percentual de aquisição externa de $\mathrm{P} \& \mathrm{D}$ sempre o dobro do patamar praticado pela indústria do país, também indica que as empresas do estudo de caso buscam maior articulação com instituições externas para a criação de conhecimento, visando influenciar de maneira positiva sua acumulação de capacidade tecnológica e também como uma maneira de compartilhar os riscos da inovação. Em outras palavras, as empresas pesquisadas estiveram buscando no período analisado a consolidação de seus esforços mediante uma estratégia proativa em inovação, especialmente se comparados à média da indústria brasileira.

De fato, o estudo de caso teve um resultado bem superior em relação ao grau de novidade de suas inovações em relação à média da indústria farmacêutica. Suas inovações em relação ao mercado nacional tiveram um comportamento destacado, lançando produtos novos para esse mercado em grande parte das vezes. Outro indicador para sinalizar que, em alguns produtos, houve o catching up tecnológico são as inovações em nível mundial, que, apesar de ainda restritas, no estudo de caso tiveram um desempenho bem superior em relação à média da indústria brasileira. Por outro lado, o percentual de inovações de nível mundial cai para a metade nas pesquisas seguintes em relação à PINTEC de 2008, e apesar também do aumento de inovações de nível nacional na PINTEC de 2011, esse indicador tem uma forte queda na última edição observada. Essas quedas percentuais podem ter sido motivadas por uma série de razões, como uma menor oferta de políticas industriais ao longo do período, assim como pela conjuntura econômica adversa que pode ter levado a uma estratégia mais conservadora no P\&D das empresas do estudo de caso..

Não obstante a boa performance da indústria farmacêutica em relação ao conjunto do setor industrial no período observado, os dispêndios em P\&D do setor e os esforços em capacidades tecnológicas ainda devem percorrer um longo caminho para que haja uma real competição com as empresas líderes do mercado mundial. Contudo, pode-se afirmar por fim que as empresas do estudo de caso sinalizaram, pelos indicadores pesquisados, que estariam capacitadas o suficiente para competições em nível mundial em certos nichos de produtos.

Finalmente é importante mencionar que outras métricas mais qualitativas para inferir o quão avançadas são as capacidades tecnológicas de uma empresa poderiam ser consideradas, a exemplo, daquelas discutidas no seminário Innovation Systems, Strategies and Policies, realizado na Universidade de Campinas em 2019, ou em Torres (2015). Estas sugestões ficam para o desenvolvimento de trabalhos futuros na mesma linha deste artigo. 


\section{Referências Bibliográficas}

BELL, M., PAVITT, K. Technological Accumulation and Industrial Growth: Contrasts Between Developed and Developing Countries. Industrial and Corporate Change, Brighton, v.2, n.2, p. 157-211, jan. 1993.

CALIARI, T., RUIZ, M. R. Brazilian pharmaceutical industry and generic drugs policy: Impacts on structure and innovation and recent developments. Science and Public Policy, Cambridge, p. 1-12, ago. 2013.

DEMIREL, P.; MAZZUCATO, M. Innovation and Firm Growth: Is R\&D Worth It?, Industry and Innovation, v. 19, n. 1, p.45 - 62, 2012.

HASENCLEVER, L. Estrutura de Mercado e Inovação. In: KUPFER, D.; HASENCLEVER, L. Economia Industrial: fundamentos teóricos e práticas no Brasil. Rio de Janeiro: Elsevier, 2013, pp. 91-101.

HASENCLEVER, L. Diagnóstico da Indústria Farmacêutica Brasileira. Relatório produzido no contexto da cooperação UNESCO/FUJB/Instituto de Economia/UFRJ (Projeto n.914BRZ58), 2002.

HASENCLEVER, L. Desafios para a indústria química. In: ANTUNES, A.; MERCADO, A. (orgs) Aprendizagem tecnológica no Brasil: a experiência da indústria química e petroquímica. Rio de janeiro: EQ/UFRJ, 1998, pp. 280-290.

MENDONÇA, S; PEREIRA, T. S.; GODINHO, M. M. Trademarks as an indicator of innovation and industrial change. Research Policy, vol. 33, 2004, p.1385-1404

MOTA, F. CASSIOLATO, J. GADELHA, C. Articulação da indústria farmacêutica brasileira com o exterior: há evidências de especialização regressiva? Cad. Saúde Pública, Rio de Janeiro, v. 28, n.3, p. 527-536, mar, 2012.

NAGAOKA, S.; MOTOHASHI, K.; AKIRA, G. Patent Statistics as an Innovation Indicator. In: HALL, B.; ROSENBERG, N. Handbooks in Economics, Elsevier, cap. 25, vol. 2,2010 .

PALMEIRA FILHO, P. Catch Up da Indústria Farmacêutica Nacional e Financiamento à Inovação: o caso da atuação do BNDES através do Profarma. Tese de Doutorado, Rio de Janeiro: Universidade Federal do Rio de Janeiro, 2013.

PARANHOS, J. ; MERCADANTE, E. ; HASENCLEVER, L. Alteração do Padrão de Esforços de Inovação das Grandes Empresas Farmacêuticas no Brasil, 2008-2011. In: HASENCLEVER, L.; OLIVEIRA, M. A.; PARANHOS, J.; CHAVES, G. (Org.). Desafios de operação e desenvolvimento do Complexo Industrial da Saúde. $1^{\text {a }}$ ed. Rio de Janeiro: Epapers Serviços Editoriais Ltda, 2016, v. 1, p. 247-278

TORRES, R. Capacitação Tecnológica na Indústria Farmacêutica Brasileira. Tese de Doutorado, Rio de Janeiro: Universidade Federal do Rio de Janeiro, 2015.

TORRES, R., HASENCLEVER, L. A Evolução Institucional das Indústrias Farmacêuticas Indiana e Brasileira Revisitadas. História econômica \& história de empresas, v. 20, n. 1, p. $1-32,2017$.

VONDELING, G. T., CAO Q., POSTMA M. J., ROZENBAUM M. H. The impact of patent expiry on drug prices: a systematic literature review. Appl Health Econ Health Policy, vol. 16 n. 5, p.653-660, 2018. 